SCCIDoc

\section{Knowledge Awareness And Practice On The Use Of Antibiotics In Endodontic Infections Among Indian Population}

Research Article

Aniruddh Menon ${ }^{1}$, Nikita Sivakumar ${ }^{2}$, Dhanraj Ganapathy ${ }^{3 *}$

${ }^{1}$ Intern, Department of Prosthodontics, Saveetha Dental College and Hospitals, Saveetha Institute of Medical and technical Sciences, Saveetha University, Chennai, India.

${ }^{2}$ Intern, Department of Prosthodontics, Saveetha Dental College and Hospitals, Saveetha Institute of Medical and technical Sciences, Saveetha University, Chennai, India.

${ }^{3}$ Professor and Head, Department of Prosthodontics, Saveetha Dental College And Hospitals, Saveetha Institute Of Medical And Technical Sciences Chennai, India.

\title{
Abstract
}

\begin{abstract}
Antibiotics have given an improved aspect to the paraphernalia that is used by various medical health practitioners for the treatment and management of various infections that are bacterial in origin and play an essential role in dental sciences as well. The aim of this study is to spread awareness on when antibiotics should and should not be used as well to assess the present status among undergraduate students about the knowledge of the same. A questionnaire was created with 14 questions and was circulated among students who have started their clinical training. 264 applicants were screened and evaluated as part of the present study. It was found thatWhen questioned whether the prescription of an antibiotic in the case of a swelling after obturation, $56.82 \%$ agreed that it was necessary whereas $27.27 \%$ did not agree and the rest were unsure. Majority of the Participants reported that the absolute indication for antibiotic prescription is Pulpitis. On questioning on the use of antibiotics for a patient with HIV, $53.79 \%$ reported that it should not be done. $45.45 \%$ of the population reported to the use of antibiotics irrespective of the presence of fever or swelling after an extraction procedure which is definitely a red flag. The most preferred antibiotic among the study population was found to be Amoxicillin. There are various aspects in which lacunae exists regarding the prescribing patterns of antibiotics in a dental practice. Further programmes are to be conducted to improve the same.
\end{abstract}

Keywords: Antibiotics; Dental; Infection; Endodontics.

\section{Introduction}

Antibiotics have given an improved aspect to the paraphernalia that is used by various medical health practitioners for the treatment and management of various infections that are bacterial in origin. There is no doubt on whether the invention and use of antibiotics is a boon or a bane as it has served its purpose in instances as a life saving drug. However, the general human population has unfortunately procured a high. and often unrealistic. expectations about when and why antibiotics should be used. The healthcare professionals have also played a significant role to the present condition with respect to the over use of antibiotics in all treatments over the last few decades $[1,2]$.
There is global problem and concern with regard to the overuse of antibiotics and the development of various forms of antibiotic resistant strains thus making the treatment with these particular organisms further more complicated [3]. Dentists contribute for approximately $10 \%$ of the total sum of antibiotics rolled out in treatment as part of primary health care and hence the development of antibiotic resistant organisms is also contributed by a regular practisingdentist [4]. For example, in the United Kingdom, it has been recorded in literature that about $40 \%$ of dental professionals prescribe antibiotic treatment for at least three times a week, around $15 \%$ prescribed antibiotic therapy to patients on a daily basis [5]. Antibiotics have not been proved to have analgesic property or reduce inflammation arising from teeth with a

*Corresponding Author:

Dhanraj Ganapathy,

Professor and Head, Department of Prosthodontics, Saveetha Dental College And Hospitals, Saveetha Institute Of Medical And Technical Sciences

Chennai, India.

E-mail: dhanraj@saveetha.com

Received: January 25, 202

Accepted: February 14, 2021

Published: February 25, 202

Citation: Aniruddh Menon, Nikita Sivakumar, Dhanraj Ganapathy. Knowledge Awareness And Practice On The Use Of Antibiotics In Endodontic Infections Among Indian Population. Int J Dentistry Oral Sci. 2021;8(2):1691-1697. doi: http://dx.doi.org/10.19070/2377-8075-21000335

Copyright: Dhanraj Ganapathy ${ }^{\circ} 2021$. This is an open-access article distributed under the terms of the Creative Commons Attribution License, which permits unrestricted use, distribution and reproduction in any medium, provided the original author and source are credited. 
periapical or endodontic infection in the absence of any systemic involvement [6]. Furthermore, there has been one Cochrane systematic review which has found no supporting evidence for the use of antibiotics for pain relief in patients with irreversible pulpitis [7]. It has been proved over time that antibiotics should be used primarily only in those patients whose immune system cannot handle the infection which might be caused. For these reasons, prescription of antibiotics by dentists should be limited [8].

Odontogenic infections, involving the coronal and radicular portions are polymocribual in nature involving a wide array of gram positive, gram negative aerobic and anaerobic organisms. When a particular group of bacteria become resistant to antibiotics they also exchange the resistance that is obtained with other bacteria [9] thus leading to a new era of antibiotic resistant species. Antibiotic sensitivity of the bacteria found within the oral cavity is gradually decreasing, and a growing number of resistant strains are being detected, in particular Porphyromonas spp. and Prevotella spp. [10]. However, within the recent decade it has also been reported that alpha haemolytic bacteria such as streptococcus viridans have obtained antibiotic resistance to groups of drugs such as macrolides, penicillin and many more [11]. Excessive use of antibiotics for inappropriate reasons not only leads to the creation to antibiotic resistant species but also increases the risk of anaphylactic reactions and various unnecessary side effects such as hepatotoxicity and nephrotoxicity [12]. In addition, antibiotic prescribing for common medical problems increases patient expectations for antibiotics, leading to a vicious cycle of increased prescribing in order to meet expectations .

In dental practice, antibiotic prescription is quintessential as the practitioner would not be aware of the particular causative organism which would be responsible for the infection sequence.. Thus, based on data from literature and epidemiology the various organisms can be estimated and suspected but treatment can only be provided through broad spectrum antibiotics [13]. The aim of this study is to spread awareness on when antibiotics should and should not be used as well to asses the present status among students about the knowledge of the same.

Ethical Approval: Verbal consent to take part in the study was obtained on administering the questionnaire designed for the study.

\section{Materials and Methods}

A questionnaire was created with 14 questions and was circulated among students who have started their clinical training. The questions were based on situations provided and whether they would prescribe an antibiotic in such a situation or that. If they were to decide to prescribe an antibiotic a question was also given for them to state the particular antibiotic they would use for the same. 264 Participants were screened as part of the study and the results thus obtained were statistically analysed.

It was checked to that all the candidates were students who had entered their clinical training or were practitioners as otherwise the results would be null and void. The questionnaire was administered through google forms also collecting the candidates mail ID and phone number and hence each response was verified. If any double entries were obtained with a different name but the same contact details the particular entry to the study was deleted as the credentials could not be verified.

The questionnaire was not limited to a particular geographic locality and was sent to a majority of dental colleges throughout India. This would also help to assess the antibiotic treatment used within the different states as well. Care was taken that the the responses obtained on a particular day were verified on the same day to ensure that all entries are verified and no entry goes unchecked.

Data was also obtained after stringent screening from various geographic localities and thus the demographics served as ways in which the data could be used to compare the use of antibiotics and awareness and practice among different places.

\section{Results}

A total of 264 participants were included as part of the study out of which the majority were undergraduate students, $74.38 \%$ (Graph 1) and the least were post graduate students. From Graph 2 it is evident that Majority of the population that were included in the study said that they would prescribe antibiotics if a patient reported with fever $(71.97 \%)$ after root canal treatment. $41.67 \%$ of the study population had not agreed that they would prescribe an antibiotic to a patient that reports to the dental operatory with limited mouth opening after a root canal treatment procedure but it is also observed that $23.48 \%$ of the population were unsure on whether to prescribe or not for the same.For a patient reporting with periapical abscess majority of the participants $(68.18 \%)$ reported to prescribe antibiotics whereas majority said (49.24\%) they would not prescribe for a patient when reported with irreversible pulpitis. When questioned whether the prescription of an antibiotic in the case of a swelling after obturation, $56.82 \%$ agreed that it was necessary whereas $27.27 \%$ did not agree and the rest were unsure. Majority of the Participants reported that the absolute indication for antibiotic prescription is Pulpitis.On questioning on the use of antibiotics for a patient with $\mathrm{HIV}, 53.79 \%$ reported that it should not be done. $45.45 \%$ of the population

Figure 1.

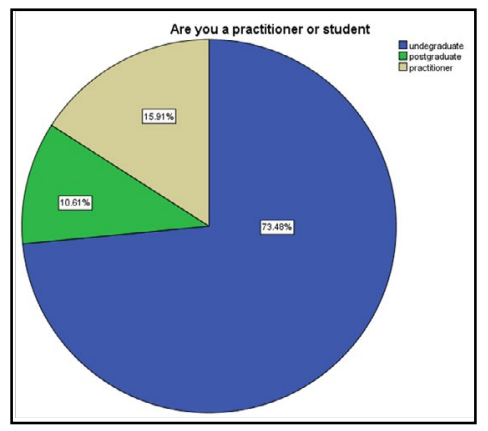


reported to the use of antibiotics irrespective of the presence of fever or swelling after an extraction procedure which is definitely a red flag. The most preferred antibiotic among the study population was found to be Amoxicillin and it was also reported that if a patient is allergic to a particular antibiotic the clinician would resort to another antibiotic. In the case of necrotic pulp $41.67 \%$ of the population said that they will not prescribe an antibiotic. $\mathrm{KMO}$ and Bartlet's statistical test revealed a significance of 0.000 .

\section{Discussion}

When the question was asked as to whether a professional would prescribe an antibiotic when a patient reports to the dental clinic with fever after a root canal treatment, $72 \%$ of the study population answered that they would prescribe an antibiotic whereas $28 \%$ of the study population answered that they would not prescribe an antibiotic (Fig 3). The fever after an RCT could be a resultant of a post operative infection and thus prescription of an antibiotic could be appropriate. However antibiotics should not be prescribed after all RCT procedures as this might amount to Antibiotic abuse [14].

On questioning whether a dentist would prescribe an antibiotic for limited mouth opening after an RCT (Fig 4) 76.5\% of the population had answered that they would not prescribe an antibiotic as they would rather prescribe a muscle relaxant, this is prov- ing that knowledge about the use of antibiotics exists among the population. Antibiotics would be required only in a few of these patients whereas in majority muscle relaxants would be sufficient and thus increased awareness should be brought about regarding the same.

The study population were then questioned whether they would prescribe an antibiotic in the case of a peri apical abscess. (Fig 5) $87.1 \%$ of the population had opted to not prescribe an antibiotic in such a situation. But, this response has its limitation as it was not mentioned whether they would prescribe the antibiotic before or after the drainage of the abscess. In North America, $68 \%$ of the dental professionals would prescribe an antibiotic in such a situation [15]. In Europe 69\% would prescribe antibiotics prior to the drainage of the abscess whereas $23 \%$ would prescribe an antibiotic after the drainage of the abscess [16]. In Croatia, $80 \%$ of the dental professionals prescribe antibiotics in the case of a peri apical abscess [17]. When there is evidence of systemic involvement and gross, rapid and diffuse spread of infection, antibiotics must be prescribed [18]. However, most chronic or even acute endodontic infections can be successfully managed by root-canal system disinfection, which eliminates the source of infection, followed by drainage of the abscess without the need for antibiotics [19].

The participants were asked whether they would prescribe an an-

Figure 2.

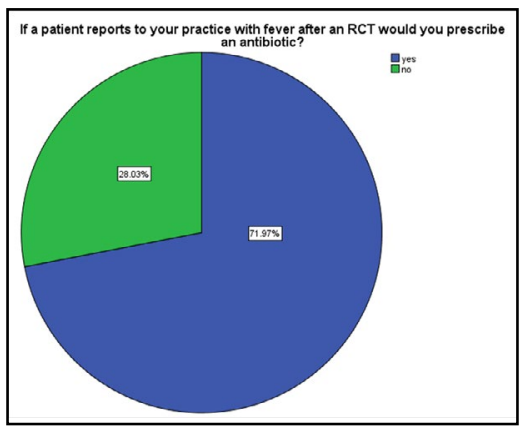

Figure 3.

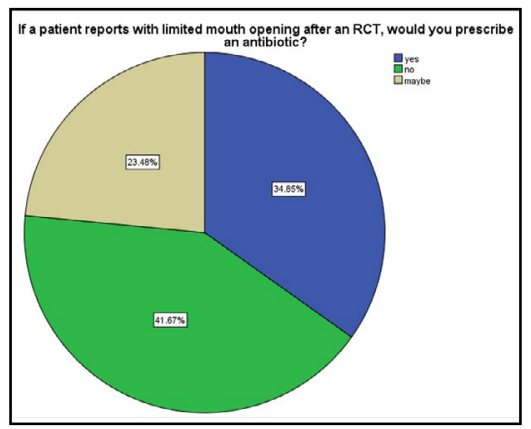

Figure 4.

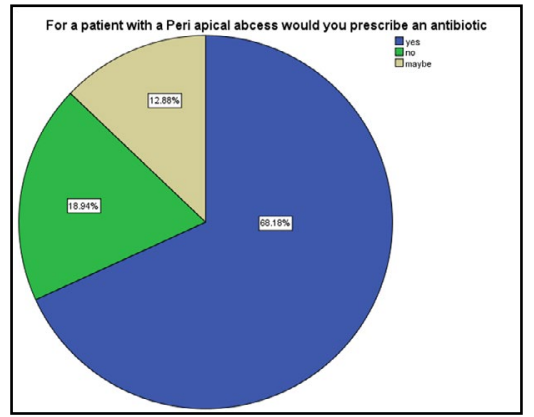


tibiotic in the case of irreversible Pulpitis, 36.4\% answered that they would prescribe an antibiotic in such a patient (Fig 6). When asked about the condition in which antibiotic prescription is absolute majority of the population 37.1\%voted for pulpitis (Fig 7). This is the most serious issue that can lead to antibiotic abuse, as when a patient presents to the dental operatory with irreversible pulpitis and the diagnosis has been confined with various testing modalities the further plan of treatment should be root canal treatment and not antibiotic therapy. However this is a problem that has been occurring in various parts of the world. In North America, 32\% of the practitioners prescribed antibiotics in the case of pulpitis [20]. In Europe $39 \%$ of the practitioners prescribed antibiotics in a patient with pulpitis [21]. In Belgium only $4.3 \%$ of the practitioners prescribed antibiotics in this situation which shows the improved knowledge available about antibiotic prescription in this geographic location [22]. 40\% of Spanish endodontists tend to prescribe antibiotics for pulpitis [23] whereas $86 \%$ of Spanish oral surgeons prescribed antibiotics when asked for a case of pulpitis [24]. Thus from all the above stated information it is evident that India is on the higher end of the table for prescription of antibiotics for pulpitis and Awareness and improved knowledge should be In forced onto the population to prevent the development of drug resistant species.

If a patient reports to the dental operatory after consuming al- cohol the participants were asked what they would do. Majority of the participants voted to send the patients home (Fig 8). This might be attributed to various reasons such as the fact that the effect of local anesthesia would be reduced and also the patient might not be as co operative as required. Symptomatic relief should be offered to the patient and then an appointment should be offered for a different date.

The study participants were asked to Rank their choice of antibiotics and the first choice antibiotic was Amoxicillin followed by Ampicillin and Clindamycin (Fig 9). The first choice antibiotic in most of the developed countries such as USA, UK, Turkey, Spain, Belgium, Croatia, Lithuania and other parts of Asia prefer Amoxicillin as the first choice of antibiotic therapy [25].

The study participants were asked to rank the cases in which they would prescribe an antibiotic, the various situations that were offered to them included pulpitis, apical periodontitis and periodontitis with periostitis. The mean highest rank was obtained by Pulpitis followed by Apical Periodontitis and Periodontitis with Periostitis( Fig 10). In a study among Lithuanian dentists, more than $60 \%$ of the respondents reported in the study to prescribing antibiotics for symptomatic apical periodontitis [22]. The majority of the respondents (84\%) reported symptomatic apical periodontitis with periostitis as being a clear indication for the prescription

Figure 5.

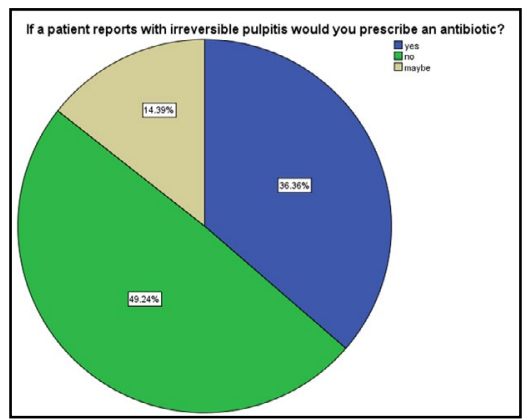

Figure 6.

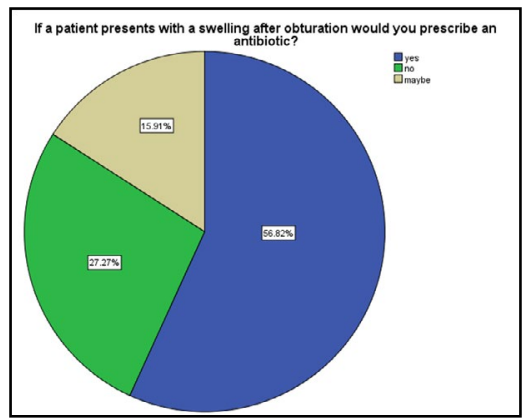

Figure 7.

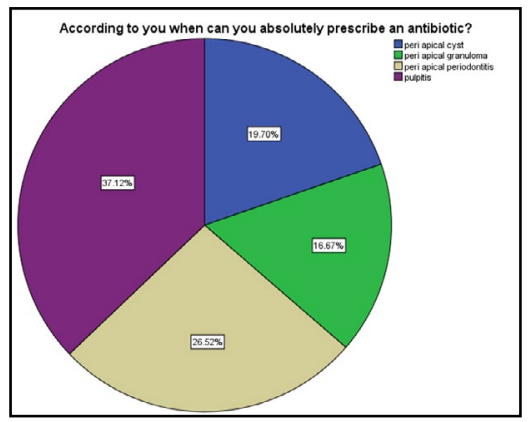


Figure 8.

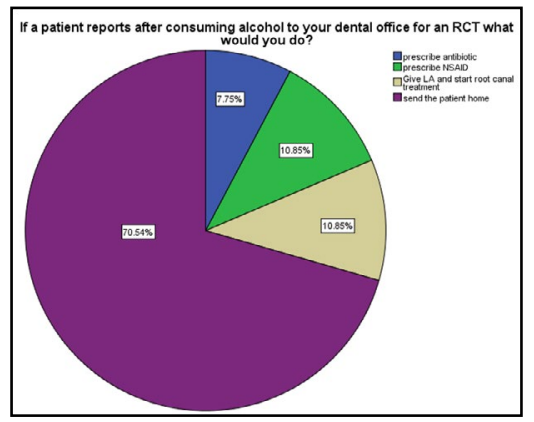

Figure 9.

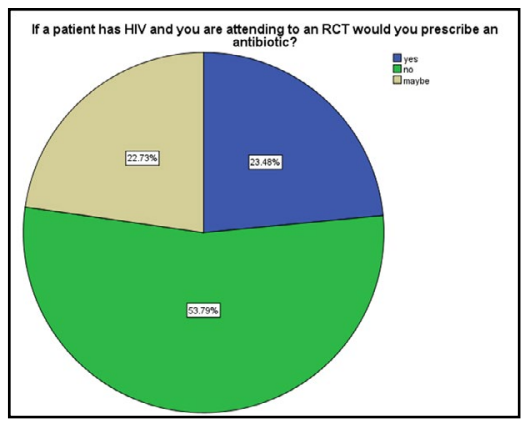

Figure 10.

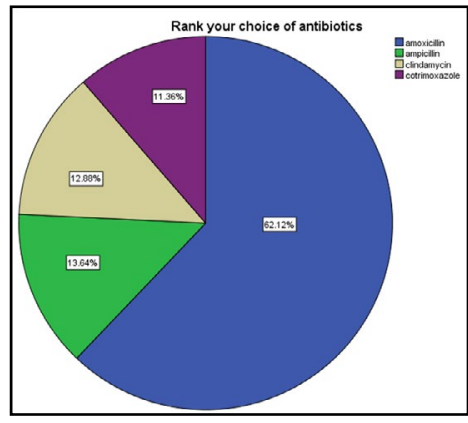

Figure 11.

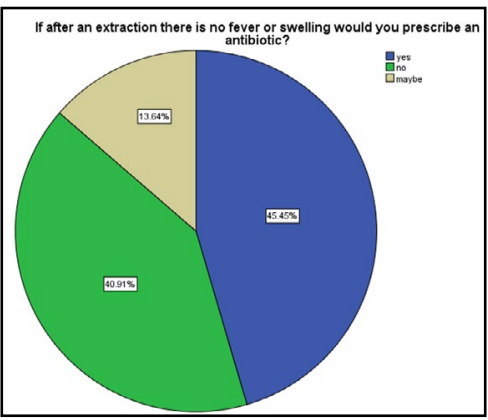

Figure 12.

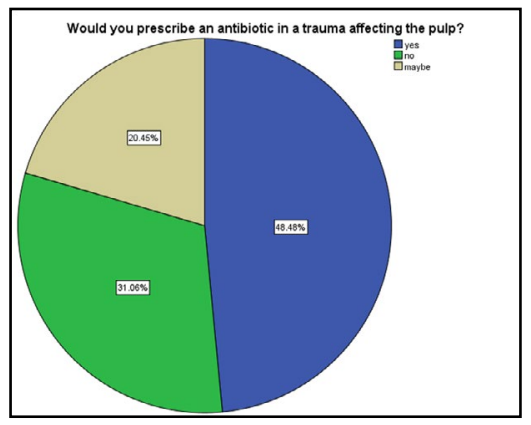


Figure 13.

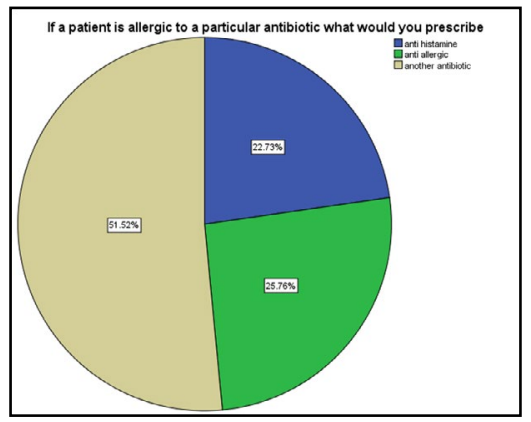

Figure 14.

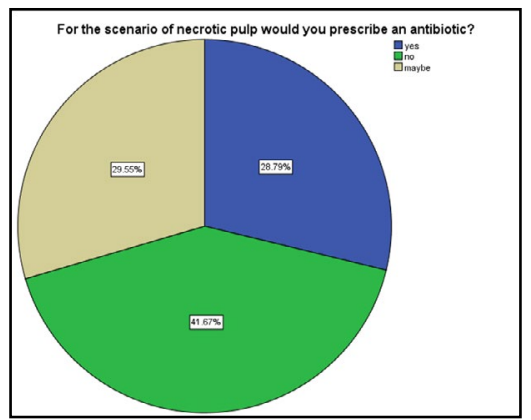

Table 1.

\begin{tabular}{|c|c|c|}
\hline \multicolumn{3}{|c|}{ KMO and Bartlett's Test } \\
\hline $\begin{array}{c}\text { Kaiser-Meyer-Olkin Measure of } \\
\text { Sampling Adequacy. }\end{array}$ & 0.533 \\
\hline $\begin{array}{c}\text { Bartlett's } \\
\text { Test of } \\
\text { Sphericity }\end{array}$ & Approx. Chi-Square & 625.404 \\
\cline { 2 - 3 } & $\mathrm{df}$ & 91 \\
\hline
\end{tabular}

of antibiotics.The most common indication in an Asian population for antibiotics was a necrotic pulp with acute apical periodontitis with swelling and moderate/severe preoperative symptoms $(92.1 \%)$ [26]. Although the above study was carried out in a different part of India there is difference in school of thought and this can be attributed to the study material or the method of teaching being followed. In a study in Europe $44 \%$ of the reported population have said that they would prescribe an antibiotic [16]. Whereas Spanish endodontists tend to prescribe antibiotics almost $22 \%$ of the times whereas Spanish surgeons tend to prescribe at an alarming rate of $71 \%$ for a patient with apical periodontitis. There is a gap in the knowledge available regarding the same and hence knowledge must be imparted.

When asked what a candidate would do if a patient is allergic to a particular antibiotic majority $(68.2 \%)$ said that they would prescribe another antibiotic whereas others had said that they would prescribe anti histamines which is completely out of question. The most commonly followed second line of antibiotics in other countries is Clindamycin and Erythromycin [25].

One of the main findings of this study is that dentists and dentists in the making are overprescribing antibiotics in the management of endodontic infections. A commonly non-indicated condition for prescription of antibiotics in systemically healthy patients is the presence of localised swelling. However, in most regions of the world for which data is available, such as North
America, Asia [26, 29], Africa [27] and Australia [28], high percentages of dentists prescribed antibiotics for this condition. It is also necessary to improve the worldwide prescribing habits of antibiotics in the treatment of endodontic infections. Moreover, various educational initiatives must be improved and developed to encourage the coherent and proper use of antibiotics in these conditions. Another important finding is that there are scarce or no data about the antibiotic-prescription patterns of dentists in many countries [30], some with large populations (such as China, Indonesia, Brazil, Bangladesh, Russia, Japan and Mexico). In these countries, adequate surveys to determine the antibiotic-prescription pattern of dentists in the treatment of endodontic infections should be encouraged.

\section{Conclusion}

Amoxicillin is the drug of choice for endodontic infections in most countries, and clindamycin and erythromycin are the drugs of choice in patients allergic to penicillin. Dentists worldwide prescribe antibiotics for conditions for which they are not indicated, such as pulpitis. There is overprescription of antibiotics in the management of endodontic infections. It is therefore necessary to amend antibiotic-prescribing habits in the treatment of endodontic infections, as well as to introduce educational initiatives to encourage the coherent and proper use of antibiotics in these conditions. 


\section{References}

[1]. Harrison JW, Svec TA. The beginning of the end of the antibiotic era? Part I. The problem: abuse of the" miracle drugs". Quintessence Int. 1998 Mar $1 ; 29(3)$.

[2]. Harrison JW, Svec TA. The beginning of the end of the antibiotic era? Part II. Proposed solutions to antibiotic abuse. Quintessence Int. 1998 Apr 1;29(4).

[3]. Abbott PV. Selective and intelligent use of antibiotics in endodontics. Aust Endod J. 2000 Apr;26(1):30-9.Pubmed PMID: 11359295.

[4]. Cope AL, Chestnutt IG. Inappropriate prescribing of antibiotics in primary dental care: reasons and resolutions. Prim Dent J. 2014 Nov;3(4):33-7.Pubmed PMID: 25668373.

[5]. Lewis MA. Why we must reduce dental prescription of antibiotics: European Union Antibiotic Awareness Day. Br Dent J. 2008 Nov 22;205(10):537-8. Pubmed PMID: 19023306.

[6]. Fouad AF, Rivera EM, Walton RE. Penicillin as a supplement in resolving the localized acute apical abscess. Oral Surg Oral Med Oral Pathol Oral Radiol Endod. 1996 May;81(5):590-5.Pubmed PMID: 8734709.

[7]. Fedorowicz Z, van Zuuren EJ, Farman AG, Agnihotry A, Al-Langawi JH. Antibiotic use for irreversible pulpitis. Cochrane Database Syst. Rev. 2013(12).

[8]. Rodriguez-Núñez A, Cisneros-Cabello R, Velasco-Ortega E, Llamas-Carreras JM, Tórres-Lagares D, Segura-Egea JJ. Antibiotic use by members of the Spanish Endodontic Society. J Endod. 2009 Sep;35(9):1198-203.Pubmed PMID: 19720216.

[9]. Jungermann GB, Burns K, Nandakumar R, Tolba M, Venezia RA, Fouad AF. Antibiotic resistance in primary and persistent endodontic infections. J Endod. 2011 Oct;37(10):1337-44.Pubmed PMID: 21924178.

[10]. Brescó Salinas M, Costa Riu N, Berini Aytés L, Gay Escoda C. Susceptibilidad antibiótica de las bacterias causantes de infecciones odontogénicas. Med Oral Patol Oral Cir Bucal . 2006 Feb;11(1):70-5.

[11]. Aracil B, Miñambres M, Oteo J, Torres C, Gómez-Garcés JL, Alós JI High prevalence of erythromycin-resistant and clindamycin-susceptible (M phenotype) viridans group streptococci from pharyngeal samples: a reservoir of mef genes in commensal bacteria. J Antimicrob Chemother. 2001 Oct;48(4):592-4.Pubmed PMID: 11581247.

[12]. Gonzales R, Malone DC, Maselli JH, Sande MA. Excessive antibiotic use for acute respiratory infections in the United States. Clin Infect Dis. $2001 \mathrm{Sep}$ 15;33(6):757-62.Pubmed PMID: 11512079.

[13]. Poveda Roda R, Bagán JV, Sanchis Bielsa JM, Carbonell Pastor E. Antibiotic use in dental practice: A review. Med Oral Patol Oral Cir Bucal (Internet). 2007 May;12(3):186-92.

[14]. AlRahabi MK, Abuong ZA. Antibiotic abuse during endodontic treatment in private dental centers. Saudi Med J. 2017 Aug;38(8):852-856.Pubmed PMID: 28762439

[15]. Dorn SO, Moodnik RM, Feldman MJ, Borden BG. Treatment of the endodontic emergency: a report based on a questionnaire-part I. J. Endod. 1977 Mar 1;3(3):94-100

[16]. Palmer NA, Pealing R, Ireland RS, Martin MV. A study of therapeutic antibiotic prescribing in National Health Service general dental practice in Eng- land. Br. Dent. J. 2000 May;188(10):554-8.

[17]. Perić M, Perković I, Romić M, Simeon P, Matijević J, Mehičić GP, et al. The Pattern of Antibiotic Prescribing by Dental Practitioners in Zagreb, Croatia. Cent Eur J Public Health. 2015 Jun;23(2):107-13.Pubmed PMID: 26851419.

[18]. Zeitoun IM, Dhanarajani PJ. Cervical cellulitis and mediastinitis caused by odontogenic infections: report of two cases and review of literature. J Oral Maxillofac Surg. 1995 Feb;53(2):203-8.Pubmed PMID: 7830190.

[19]. Segura-Egea JJ, Velasco-Ortega E, Torres-Lagares D, Velasco-Ponferrada MC, Monsalve-Guil L, Llamas-Carreras JM. Pattern of antibiotic prescription in the management of endodontic infections amongst Spanish oral surgeons. Int Endod J. 2010 Apr;43(4):342-50.Pubmed PMID: 20487455.

[20]. Sivaraman SS, Hassan M, Pearson JM. A national survey of pediatric dentists on antibiotic use in children. Pediatr Dent. 2013;35(7):546-9.Pubmed PMID: 24553280

[21]. Tulip DE, Palmer NO. A retrospective investigation of the clinical management of patients attending an out of hours dental clinic in Merseyside under the new NHS dental contract. Br Dent J. 2008 Dec 20;205(12):659-64. Pubmed PMID: 19057559.

[22]. Skučaitė N, Pečiulienė V, Manelienė R, Mačiulskienė V. Antibiotic prescription for the treatment of endodontic pathology: a survey among Lithuanian dentists. Medicina. 2010 Dec;46(12):806.

[23]. Rodriguez-Núñez A, Cisneros-Cabello R, Velasco-Ortega E, Llamas-Carreras JM, Tórres-Lagares D, Segura-Egea JJ. Antibiotic use by members of the Spanish Endodontic Society. J Endod. 2009 Sep;35(9):1198-203.Pubmed PMID: 19720216.

[24]. Segura-Egea JJ, Velasco-Ortega E, Torres-Lagares D, Velasco-Ponferrada MC, Monsalve-Guil L, Llamas-Carreras JM. Pattern of antibiotic prescription in the management of endodontic infections amongst Spanish oral surgeons. Int Endod J. 2010 Apr;43(4):342-50.Pubmed PMID: 20487455.

[25]. Segura-Egea JJ, Martín-González J, del Carmen Jiménez-Sánchez M, Crespo-Gallardo I, Saúco-Márquez JJ, Velasco-Ortega E. Worldwide pattern of antibiotic prescription in endodontic infections. Int. Dent. J. 2017 Aug 1;67(4):197-205.

[26]. Kumar KP, Kaushik M, Kumar PU, Reddy MS, Prashar N. Antibiotic prescribing habits of dental surgeons in hyderabad city, India, for pulpal and periapical pathologies: a survey. Adv Pharmacol Sci. 2013;2013:537385. Pubmed PMID: 24187549.

[27]. Al-Haroni M, Skaug N. Knowledge of prescribing antimicrobials among Yemeni general dentists. Acta Odontol Scand. 2006 Oct;64(5):274-80.Pubmed PMID: 16945892.

[28]. Jaunay T, Dambrook P, Goss A. Antibiotic prescribing practices by South Australian general dental practitioners. Aust. Dent. J. 2000 Sep;45(3):17986.

[29]. Kakoei S, Raoof M, Baghaei F, Adhami S. Pattern of Antibiotic Prescription among Dentists in Iran. Iran Endod J. 2007 Spring;2(1):19-23.Pubmed PMID: 24348653.

[30]. Dar-Odeh NS, Abu-Hammad OA, Al-Omiri MK, Khraisat AS, Shehabi AA. Antibiotic prescribing practices by dentists: a review. Ther Clin Risk Manag. 2010;6:301. 